\title{
Utilization of Open Educational Resources in Mathematics Instruction for the Intermediate School
}

\author{
Eman A. Assiri (Corresponding author) \\ Ministry of Education, Kingdom of Saudi Arabia \\ E-mail: eman_asery@yahoo.com \\ Mohammed A. Alnatheer \\ Faculty of Education, King Saud University, Kingdom of Saudi Arabia \\ E-mail: alnatheer@ksa.edu.sa
}

Received: November 21, 2019 Accepted: December 20, 2019

Published: December 30, 2019

doi:10.5296/jei.v5i2.15898 URL: https://doi.org/10.5296/jei.v5i2.15898

\begin{abstract}
The present study aimed to examine the extent of utilizing Open Educational Resources (OER) in mathematics instruction for the intermediate school in Riyadh, Saudi Arabia. It also aimed at identifying the benefits, the challenges, and the opportunities of applying OER in the educational process. For achieving the study objectives, the descriptive analytical approach was adopted. The study population comprised all the teachers of the intermediate school in Riyadh. A questionnaire was prepared and applied to a randomly selected sample of (113) teachers of the intermediate school. In the light of the findings, a set of recommendations and further studies were formulated.
\end{abstract}

Keywords: Open educational resources, Mathematics instruction, Intermediate school

\section{Introduction}

The educational institutions have experienced significant changes and developments since the introduction of the computer and the Internet with their various applications. They have affected clearly access to the different cultures of the world. Therefore, such institutions should compete to promote education to keep up with progress because they are evaluated by the services they provide to students. Additionally, the roles in these institutions are changing. The teacher turns into an adviser and the student shifts from a passive learner to a researcher and investigator. Consequently, education has shifted from course-based information to OER. 
The OER is a new teaching and learning method, which helps provide an interactive learning environment with a robust design, allowing the learner to engage constructively and disseminate knowledge.

Kozinska et al. (2010) and Al-tal (2013) reported that utilizing OER has several benefits, including the democratization of education and equal educational opportunities. Khan Academy, Rewaq, and HaveMath, etc. are examples of OER. Jones (2018) examined the impact of Khan Academy on mathematics achievement among the second-grade students in California. The study reported the importance of implementing the OER outside the classroom as a teaching aid by the teacher. For the student, they enhance achievement in mathematics and other subjects. Kelly (2018) investigated the impact of using Khan Academy as mathematics remediation among the ninth- graders in Virginia. Although the study did not report significant differences in achievement, it improved the students' learning motivation and made them responsible for their learning by exerting effective efforts in the classroom.

Mathematics is one of the accurate scientific subjects with precise modules. Hence, it is difficult to achieve a level without passing the prior ones, making it more difficult to learn and teach mathematics. Al-Rwimi (2017) illustrated that one of the reasons for the lowachievement level in mathematics is the lack of interesting teaching methods. In addition, is important to give the learners the opportunity to search for information in different educational resources provided by the teacher to guide them to sound thinking and creativity in mathematics.

Therefore, the author argues that there is a need to examine the utilization of OER in mathematics instruction, especially for the intermediate school. It requires that the learner should deeply understand the mathematical concepts and master the skills required to work out the different problems accurately and quickly.

\subsection{Statement of the Problem}

The author has noticed the intermediate school students' reluctance to study mathematics as a result of their misconception about mathematics, claiming that it is more complicated in the advanced stages. Additionally, many mathematical problems require high skills and speed. This misconception may be raised due to the teaching method that may be traditional, inefficient, and based on memorization. Consequently, the students make many mistakes, even at the advanced stages. This restricts receiving useful feedback.

Many studies report the low achievement level in mathematics. For example, Abu Assad (2010) argued that the traditional methods adopted by the teacher are useless. Joiner, Darling, Drew, and Huang (2012) indicated that the educational environment plays a significant role in teaching all subjects, especially mathematics because it is characterized by accumulation and abstraction. What is taught is mostly the application of the theoretical part. Thus, the learner cannot feel the beauty and features of mathematics that is considered as the second national language worldwide. Mursi, Kamal, Al-husini, and Mohammed (2013) reported that mathematics is involved in all the other scientific and the theoretical subjects and seeks the 


\section{Macrothink}

appropriate solutions. However, most students do not seek this aspect, as shown by the result of Saudi Arabia in the Trends in International Mathematics and Science Study (TIMSS) that is ranked among the least countries. Al-Shamrani (2009) argued that it was better for the participants in TIMSS to choose the answers randomly than relying on the prior cognitive background. The Fifth Scientific Conference held by the Saudi Ministry of Education (2015) recommended deepening concepts and enabling the learner to perform mathematical skills at various stages of general education. The Second Conference of Excellence in Science and Mathematics (2017) aimed to employ modern methods in mathematics learning and instruction and to highlight the fruitful experience that enhanced the students' achievement level.

Therefore, the problem of the study has been defined in examining the extent of utilizing OER in mathematics instruction for the intermediate school. It also aimed at identifying the benefits, the challenges, and the opportunities of applying OER in the educational process.

\subsection{Questions}

The study seeks to answer the following questions:

(1) What are the benefits of utilizing OER in mathematics instruction for the intermediate school?

(2) What are the challenges to utilizing OER in mathematics instruction for the intermediate school?

(3) What are the opportunities for utilizing OER in mathematics instruction for the intermediate school?

\subsection{Objectives}

The study aims to examine the extent of utilizing OER in mathematics instruction for the intermediate school by identifying the benefits, the challenges, and the opportunities of their application in the educational process.

\subsection{Significance}

The study may benefit:

(1) The learners to disseminate the utilization of OER and to allow them to participate and gain and share the experience.

(2) The teacher to access technological innovations and employ technology in the teaching process to help the learner understand mathematical concepts and master mathematical skills.

(3) The author to conduct further relevant studies.

\subsection{Limitations}

$\checkmark$ Objective limitations: OER in mathematics instruction for the intermediate school.

$\checkmark$ Spatial limitations: The intermediate schools of North Riyadh Education Office. 
Temporal limitations: The second semester of 2018-2019.

\subsection{Definition of Terms}

OER are unlimited electronic media that allow the teacher to contact students worldwide anytime and anywhere for free. They help share the content and files to enrich the learning and teaching process.

\subsection{Theoretical Framework}

\subsubsection{Concept and Origin of OER}

Because it is the first pillar of creating a knowledge-based society, education helps provide the required skills for economic, political, and social development. Moreover, technology is a significant tool for preparing and educating the individual with information that helps achieve cultural and professional growth at the time of overwhelming information and technological advancement. Inspired by the success of Open Sources Initiative (OSI), David Wiley founded Open Content Project in 1998 and argued that the educational content should be free and accessible (Yuan, MacNeill, \& Kraan, 2008). He used the term OER for the first time in UNESCO's forum in 2002 when discussing the impact of open courseware for higher education in developing countries. In its second forum in 2004, UNESCO expanded the concept of OER to include three important aspects of the educational process, namely educational content, tools and operational resources (Al-tal, 2013). McShane (2017) defines OER as an educational platform that allows sharing and modifying the educational content under an intellectual property license that enables free use at any time. Colvard, Watson, and Park (2018) report that OER are software or open-source tools that provide educational content at low cost and high quality. They can connect all teachers and students across the world to share experience and ideas in any subject. The author argues that OER are technological aids in the educational process for the students who need to re-explain many mathematical concepts without boredom and in a different style that matches the mental abilities of the students before engagement with other classmates.

\subsubsection{Benefits of Utilizing OER}

In the light of the increasing confidence in utilizing OER worldwide, many advantages have been gained. Williams (2010), Yang and Cotera (2011), McShane (2017), and Colvard et al. (2018) report some advantages as follows:

$\checkmark$ They can provide flexible education to students who encounter family and social pressures by allowing them to pursue education.

$\checkmark \quad$ They bridge the gap between formal and informal education.

$\checkmark$ They provide continuing professional education to reform and develop the local economy.

$\checkmark \quad$ They encourage the students to engage in active, participatory, and collaborative learning by having fruitful discussions about some topics of interest. 
$\checkmark$ They inform the student on different curricula of the world in a simple and easy way.

$\checkmark$ They accommodate all national abilities, especially the governmental and private universities, to attract many students to participate in the available tests at a nominal fee only.

$\checkmark$ They increase employment opportunities for university graduates.

$\checkmark$ They help overcome the shortfall of teachers' preparation in different countries.

In this regard, Chiorescu (2017) stresses that OER have contributed to reducing the cost for many students who had to pay about $\$ 1200$ for the books and the school supplies annually, motivating them to drop out especially after the high school completion. Jones (2018) reports that the use of OER helps change the attitude and negative perception of primary school students to mathematics.

\subsubsection{Challenges and Opportunities of Applying OER}

OER have attracted increasing attention worldwide due to their key role in providing flexible learning opportunities. They also help develop knowledge and they are easily used when digitized (Al-tal, 2013). However and according to Yuan et al. (2008), Falconer, Littlejohn, McGill, and Beetham (2016), Dutta (2016), and Ganapathi (2018), OER encounter many challenges and obstacles. They include the lack of the policies that assert the pedagogical and educational innovations in the organizational change of higher education institutions, the difficulty to have a balanced approach to effective cross-cultural communication, as well as the lack of the communication and cooperation between the institutions and the developers of teachers and students. Moreover, the international bodies do not motivate the finance of new projects to produce learning resources, there is not a permanent digital multi-lingual and multimedia repository, some students do not have computers due to limited income, and the culture of its use and significance in the learning process is poorly disseminated. The lack of organizing online learning activities and materials that can help develop curricula in different general and higher education stages also plays a role. According to Yang and Cotera (2011), the utilization and production of OER underline a real need for establishing an educational city that allows for the exchange of the best experience and practices to create a new learning system that helps embody lifelong learning across academic education.

Dutta (2016) and Ganapathi (2018) report that OER provide many educational opportunities for the teacher, the student, and the educational process as a whole. They reinforce the individual's learning and teaching, develop a mechanism for improving and enriching the quality of general and higher education, and create an intellectual capital for innovation and creativity in various fields. They also inform the individual about foreign cultures, providing an opportunity for the faculty members to produce OER as one of the bases of scientific promotion. In addition, they help the teacher develop a professional specialization and improve the ability to master computer skills (Jones, 2018). 


\section{MlMacrothink}

\section{Methodology}

\subsection{Method}

The present study adopted the descriptive analytical approach because it examines the phenomenon in reality, describe it accurately, and expresses it qualitatively and quantitatively.

\subsection{Population and Sampling}

The population covered all the female teachers of the Riyadh Education Offices for the intermediate school. The questionnaire was distributed to all Riyadh offices numbered (9) and a large number of responses were received about (432). The North Riyadh Education Office was ranked the highest with (113) responses, representing the sample of the study. Based on the statistical methods, the nature, description, and classification of the study sample were obtained.

\subsubsection{Distribution of the Sample According to the Years of Experience}

The frequencies and percentages of the study sample were calculated according to the years of experience, as shown in Table 1.

Table 1. The frequencies and percentages of the study sample according to the years of experience

\begin{tabular}{|l|l|l|}
\hline Years of experience & Number & Percentage \\
\hline Less than (6) years & 31 & $27.4 \%$ \\
\hline From 6 to less than (11) years & 36 & $31.9 \%$ \\
\hline From (11) to less than (16) years & 17 & $15.0 \%$ \\
\hline More than (16) years & 29 & $25.7 \%$ \\
\hline Total & 113 & $100 \%$ \\
\hline
\end{tabular}

Table 1 shows that most of the participants have from (6) to less than (11) years of experience, rating $(31.9 \%)$.

\subsubsection{Distribution of the Sample According to Utilizing OER in Instruction}

The frequencies and percentages of the study sample were calculated according to utilizing OER in instruction, as shown in Table 2. 


\section{Macrothink}

Table 2. The frequencies and percentages of the study sample according to utilizing OER in instruction

\begin{tabular}{|l|l|l|}
\hline Utilizing OER in instruction & Number & Percentage \\
\hline Yes & 66 & $58.4 \%$ \\
\hline No & 47 & $41.6 \%$ \\
\hline Total & 113 & $100 \%$ \\
\hline
\end{tabular}

Table 2 shows that that most of the participants utilize OER in instruction, rating $(58.4 \%)$ compared to $(41.6 \%)$ who have never utilized them.

\subsection{Tool (Developed by the Author)}

The study employed a closed questionnaire as the main tool of data collection to answer the questions and to achieve the objectives. In addition, the collected data are easy to group and classify. By reviewing literature such as Al-tal (2013), Williams (2010), and Yuan et al. (2008), utilizing some relevant tools, and consulting professors and educators at local and regional universities, the items were formulated. Then, the questionnaire was reviewed by the reviewers and was modified based on their notes.

$\checkmark$ Setting the objective: The questionnaire aimed to examine the extent of utilizing OER in mathematics instruction for the intermediate school.

$\checkmark$ Defining the domains: The following domains were defined.

(a) Advantages of utilizing OER in mathematics instruction for the intermediate school with (9) items.

(b) Challenges to utilizing OER in mathematics instruction for the intermediate school with (7) items.

(c) Opportunities for utilizing OER in mathematics instruction for the intermediate school with (7) items.

$\checkmark \quad$ The questionnaire's content and items: The items were formulated in the light of the predefined domains to be related to the domain and the subject. In its first draft, the scale comprised (24) items distributed to all domains. They were formulated in an easy and simple way. The questionnaire was based on Likert scale (strongly agree, agree, undecided, disagree, and strongly disagree) and rated $(5,4,3,2$, and 1) respectively for the positive phrases and (1, $2,3,4$, and 5) for the negative ones.

$\checkmark$ Instructions: General information was given about the teacher. If she has a background and experience in OER, she completes the questionnaire. If she does not have any background, she stops answering it. 
The scale's response: The scale was electronically developed via Google Forms. All the questions were mandatory except for the name. Additionally, the teacher is not allowed to move from one domain to the next without answering all items.

The scale's reviewing and final draft: The scale was reported to the evaluators to review its items in terms of consistency and linguistic correctness. A reviewer reported modifying two items without deleting or adding any others.

Pilot study: After preparing and reviewing the scale, it was applied to a pilot sample of (10) teachers from the population. Based on the results, the following items were estimated:

Validity: The validity was estimated by calculating the correlation coefficient of every item and its domain, as shown in Table 3.

Table 3. Correlation coefficients between the degree of each domain and the total degree of the questionnaire

\begin{tabular}{|l|l|}
\hline Domain & Correlation coefficient \\
\hline Advantages of utilizing OER & $0.938^{* *}$ \\
\hline Challenges to utilizing OER & $0.941^{* *}$ \\
\hline Opportunities for utilizing OER & $0.883^{* *}$ \\
\hline
\end{tabular}

Note. ** Statistically significant at the level of (0.01).

Table 3 illustrates that the values of correlation coefficients for the three domains to the total mark of the questionnaire were high and rated (0.883-0.941). They were statistically significant at the level of (0.01).

$\checkmark$ Reliability: The scale's reliability was calculated using Cronbach's alpha and scored (0.920). It is a high value, indicating the scale's reliability, as shown in Table 4.

Table 4. Reliability coefficients of the tool according to the domains

\begin{tabular}{|l|l|l|}
\hline Domain & Number of items & Cronbach's alpha \\
\hline Advantages of utilizing OER & 9 & 0.849 \\
\hline Challenges to utilizing OER & 7 & 0.884 \\
\hline Opportunities for utilizing OER & 7 & 0.901 \\
\hline Total & 23 & 0.920 \\
\hline
\end{tabular}

After verifying the validity and reliability of the questionnaire, its final draft is formulated (Appendix 1). 


\section{Mll Macrothink}

Applying the tool (questionnaire): The questionnaire was distributed via social media (Twitter and WhatsApp) in addition to distributing a hard copy to some teachers who were easily accessed by the author. Although all methods of increasing the number of responses were adopted, the responses numbered (113). This was due to the difficulty of accessing all the teachers at the schools of North Riyadh Education Office because of the big area of the capital. After that, the data were statistically analyzed and the results were concluded.

\section{Results}

The study aimed at examining the extent of utilizing Open Educational Resources (OER) in mathematics instruction for the intermediate school in Riyadh. To answer the questions, a questionnaire was prepared and applied to a sample of (113) teachers at the intermediate schools of North Riyadh Education Office in the second semester of 2018-2019. The data were entered into the computer and analyzed using the statistical program (SPSS).

\subsection{Answer to the First Question}

In order to answer this question, (9) items were formulated. The following results were obtained: 
Table 5. The means, standard deviations, and ranking of the responses to "the benefits of utilizing OER in mathematics instruction for the intermediate school" in descending order according to the arithmetic means

\begin{tabular}{|l|l|l|l|l|l|l|}
\hline SN & Item & Mean & Percentage & $\begin{array}{l}\text { Standard } \\
\text { deviation }\end{array}$ & Agreement & Ranking \\
\hline 2 & $\begin{array}{l}\text { They are not limited to a certain } \\
\text { nationality and available } \\
\text { to all free of charge. }\end{array}$ & 4.72 & $93 \%$ & 0.453 & Strongly agree & 1 \\
\hline 9 & $\begin{array}{l}\text { They offer the repetition of information } \\
\text { and training more than once. }\end{array}$ & 4.71 & $93 \%$ & 0.494 & Strongly agree & 2 \\
\hline 6 & $\begin{array}{l}\text { They enable the learner to benefit } \\
\text { from others' experience. }\end{array}$ & 4.69 & $92 \%$ & 0.501 & Strongly agree & 3 \\
\hline 5 & $\begin{array}{l}\text { They allow the student to participate } \\
\text { freely in fruitful discussions with } \\
\text { others around the world. }\end{array}$ & 4.65 & $91 \%$ & 0.596 & Strongly agree & 4 \\
\hline 4 & $\begin{array}{l}\text { The student takes the responsibility to } \\
\text { learn himself/herself (self-censorship). }\end{array}$ & 4.64 & $91 \%$ & 0.642 & Strongly agree & 5 \\
\hline 8 & $\begin{array}{l}\text { They save time and effort in the } \\
\text { educational process. }\end{array}$ & 4.25 & $81 \%$ & 0.527 & Strongly agree & 6 \\
\hline 3 & $\begin{array}{l}\text { They allow the student to choose } \\
\text { freely the courses of interest. }\end{array}$ & 4.24 & $81 \%$ & 0.505 & Strongly agree & 7 \\
\hline 1 & $\begin{array}{l}\text { They do not restrict the student } \\
\text { to a specific time and place. }\end{array}$ & 4.23 & $81 \%$ & 0.518 & Strongly agree & 8 \\
\hline 7 & $\begin{array}{l}\text { The subject is presented in } \\
\text { a simple and clear manner. }\end{array}$ & 4.23 & $81 \%$ & 0.482 & Strongly agree & 9 \\
\hline Total & \begin{tabular}{l} 
Ing \\
\hline
\end{tabular} & $87 \%$ & 0.385 & Strongly agree \\
\hline
\end{tabular}

Table 5 shows that the benefits of utilizing OER in mathematics instruction for the intermediate school from teacher's perspective were rated (strongly agree) with an arithmetic mean of (4.48 out of 5.00). In addition, the responses varied and the means ranged (from 4.23 to 4.72 out of 5), indicating (strongly agree). While the item (they are not limited to a certain nationality and available to all free of charge) was ranked first (strongly agree) with an arithmetic mean of (4.72) and a percentage of (93\%), the item (they offer the repetition of information and training more than once) was ranked second (strongly agree) with an arithmetic mean of (4.71) and a percentage of (93\%). The item (they enable the learner to benefit from others' experience) was ranked third (strongly agree) with an arithmetic mean of (4.69) and a percentage of (92\%). The item (they allow the student to participate freely in fruitful discussions with others around the world) was ranked fourth (strongly agree) with an arithmetic mean of (4.65) and a percentage of (91\%). Furthermore, the item (the student takes 
the responsibility to learn himself/herself (self-censorship) was ranked fifth (strongly agree) with an arithmetic mean of (4.64) and a percentage of (91\%). The item (they save time and effort in the educational process) was ranked sixth (strongly agree) with an arithmetic mean of (4.25) and a percentage of (81\%). It slightly differed from the item (they allow the student to choose freely the courses of interest) that was ranked seventh (strongly agree) with an arithmetic mean of (4.24) and a percentage of (81\%). The last two items (they do not restrict the student to a specific time and place) and (the subject is presented in a simple and clear manner) were rated the same (strongly agree) with an arithmetic mean of (4.23) and a percentage of $(81 \%)$.

\subsection{Answer to the Second Question}

In order to answer this question, (7) items were formulated. The following results were obtained:

Table 6. The means, standard deviations, and ranking of the responses to "the challenges to utilizing OER in mathematics instruction for the intermediate school " in descending order according to the arithmetic means

\begin{tabular}{|l|l|l|l|l|l|l|}
\hline SN & Item & Mean & Percentage & $\begin{array}{l}\text { Standard } \\
\text { deviation }\end{array}$ & Agreement & Ranking \\
\hline 4 & $\begin{array}{l}\text { Lack of computers to the } \\
\text { students' numbers }\end{array}$ & 4.62 & $90 \%$ & 0.849 & Strongly agree & 1 \\
\hline 6 & $\begin{array}{l}\text { Lack of disseminating the culture } \\
\text { of OER utilization among students }\end{array}$ & 4.62 & $90 \%$ & 0.771 & Strongly agree & 2 \\
\hline 5 & Lack of adequate time in class & 4.51 & $88 \%$ & 0.974 & Strongly agree & 3 \\
\hline 7 & $\begin{array}{l}\text { The teachers' concern about OER } \\
\text { utilization in the classroom }\end{array}$ & 4.26 & $81 \%$ & 1.148 & Strongly agree & 4 \\
\hline 1 & Different courses & 3.81 & $70 \%$ & 0.492 & Agree & 5 \\
\hline 2 & $\begin{array}{l}\text { Difficulty to look for resources } \\
\text { suitable for the age group }\end{array}$ & 3.69 & $67 \%$ & 0.614 & Agree & 6 \\
\hline 3 & Difficulty to define student achievement & 3.12 & $53 \%$ & 0.579 & Undecided & 7 \\
\hline Total & 4.09 & $77 \%$ & 0.543 & Agree & \\
\hline
\end{tabular}

Table 6 shows that the challenges to utilizing OER in mathematics instruction for the intermediate school was rated (agree) from the teachers' perspective with an arithmetic mean of (4.9 out of 5). The responses varied and the means ranged (from 4.23 to 4.72 out of 5), indicating (undecided, agree, and strongly agree), respectively. The item (lack of computers to the students' numbers) was ranked first (strongly agree) with an arithmetic mean of (4.62) and a percentage of $(90 \%)$, while the item (lack of disseminating the culture of OER utilization among students) was ranked second (strongly agree) with an arithmetic mean of 
(4.62) and a percentage of (90\%). The item (lack of adequate time in class) was ranked third (strongly agree) with an arithmetic mean of (4.51) and a percentage of (88\%). The item (the teachers' concern about OER utilization in the classroom) was ranked fourth (strongly agree) with an arithmetic mean of (4.26) and a percentage of (81\%). The item (different courses) was ranked fifth (agree) with an arithmetic mean of (3.81) and a percentage of (70\%). The item (difficulty to look for resources suitable for the age group) was ranked sixth (agree) with an arithmetic mean of (3.69) and a percentage of (67\%), while the item (difficulty to define student achievement) was ranked seventh (undecided) with an arithmetic mean of (3.12) and a percentage of $(53 \%)$.

\subsection{Answer to the Third Question}

In order to answer this question, (7) items were formulated. The following results were obtained:

Table 7. The means, standard deviations, and ranking of the responses "the opportunities for utilizing OER in mathematics instruction for the intermediate school" in descending order according to the arithmetic means

\begin{tabular}{|l|l|l|l|l|l|l|}
\hline SN & Item & Mean & Percentage & $\begin{array}{l}\text { Standard } \\
\text { deviation }\end{array}$ & Agreement & Ranking \\
\hline 2 & $\begin{array}{l}\text { They inform the teacher about } \\
\text { new and different experience. }\end{array}$ & 4.73 & $93 \%$ & 0.463 & Strongly agree & 1 \\
\hline 1 & $\begin{array}{l}\text { They help the teacher } \\
\text { master computer skills. }\end{array}$ & 4.67 & $92 \%$ & 0.589 & Strongly agree & 2 \\
\hline 3 & $\begin{array}{l}\text { They help resolve some } \\
\text { educational problems in } \\
\text { traditional classrooms. }\end{array}$ & 4.65 & $91 \%$ & 0.691 & Strongly agree & 3 \\
\hline 5 & $\begin{array}{l}\text { They reduce the extent of stress } \\
\text { and anxiety about mathematics } \\
\text { in the classroom. }\end{array}$ & 4.56 & $89 \%$ & 0.731 & Strongly agree & 4 \\
\hline 6 & $\begin{array}{l}\text { They develop the skills of creative } \\
\text { thinking among the students through } \\
\text { various interactive activities. }\end{array}$ & 4.20 & $80 \%$ & 0.554 & Strongly agree & 5 \\
\hline 7 & $\begin{array}{l}\text { They help the students master many } \\
\text { mathematical concepts and skills. }\end{array}$ & 4.20 & $80 \%$ & 0.569 & Strongly agree & 6 \\
\hline 4 & $\begin{array}{l}\text { They motivate the student to be } \\
\text { engaged more with classmates. }\end{array}$ & 4.15 & $79 \%$ & 0.570 & Agree & 7 \\
\hline Total & 4.45 & $86 \%$ & 0.436 & Strongly agree \\
\hline
\end{tabular}

Table 7 illustrates that the opportunities for utilizing OER in mathematics instruction for the 
intermediate school were rated (strongly agree) from the teachers' perspective with an arithmetic mean of (4.48 out of 5). The responses varied and the means ranged (from 4.15 to 4.73 out of 5), indicating (agree and strongly agree), respectively. The item (they inform the teacher about new and different experience )was ranked first (strongly agree) with an arithmetic mean of (4.73) and a percentage of (93\%), while the item (they help the teacher master the computer skills) was ranked second (strongly agree) with an arithmetic mean of (4.67) and a percentage of (92\%). The item (they help resolve some educational problems in traditional classrooms) was ranked third (strongly agree) with an arithmetic mean of (4.65) and a percentage of (91\%). The item (they reduce the extent of stress and anxiety about mathematics in the classroom) was ranked fourth (strongly agree) with an arithmetic mean of (4.56) and a percentage of (89\%). The item (they develop the skills of creative thinking among the students through various interactive activities) was ranked fifth (strongly agree) with an arithmetic mean of (4.20) and a percentage of (80\%). The item (they help the students master many mathematical concepts and skills) was ranked sixth (strongly agree) with an arithmetic mean of (4.20) and a percentage of (80\%). The item (they motivate the student to be engaged more with classmates) was ranked seventh (agree) with an arithmetic mean of (4.15) and a percentage of (79\%).

\section{Findings}

The author found out that the Central Region's teachers access the latest technological innovations due to their location (the capital) with its large area that includes different Arab and foreign nationalities. Thus, the teacher encounters a constant challenge of developing the educational practices inside and outside the classroom. This result matches the findings of Yuan et al. (2008) and Williams (2010), concluding that the utilization of OER faces many challenges and obstacles to the teacher and the learner in the higher and general education. The study also matches the results of Dutta (2016), Chiorescu (2017), Jones (2018), Kelly (2018), and Colvard et al. (2018), reporting that the benefits of utilizing OER in mathematics instruction. They affect the students, change their attitudes, and increase their achievements. Because they take a long time of implementation, they raise the teacher's concern about utilization in instruction. The study differs from other studies in terms of the approach and the educational stage. For example, Jones (2018) was applied to the primary stage Kelly (2018) was applied to the high school. They both employed qualitative and quantitative approaches.

\section{Conclusion}

The present study aimed at examining the extent of utilizing OER in mathematics instruction for the intermediate school as a transitional stage that is characterized by abstraction and complexity in subjects. It is hoped that it will be a starting point for further studies that may help investigate how the teacher can utilize OER with students. The author suggests developing an evaluation tool to highlight the mechanism of utilizing OER. Furthermore, further studies may be applied to other regions in Saudi Arabia.

\section{References}

Abu Assad, S. (2010). Methods of teaching mathematics. Amman: Dar Al-Shorok For 
Publishing \& Distribution.

Al-Rwimi, D. (2017). Modern methods of teaching mathematics. Paper presented at the First Mathematics Conference: Compatibility of Secondary and University Curricula in Mathematics, College of Science, Asmarya University for Islamic Sciences.

Al-Shamrani, S. (2009). Report on the results of Saudi Arabia's participation in the Trends in International Mathematics and Science Study. KSA: The Excellence Center of Science and Mathematics Education, King Saud University.

Al-tal, K. (2013). Open educational resources: The challenges of teaching and learning in the Arab countries. Paper presented at the Second International Conference of Omani Society for Educational Technology, Oman.

Chiorescu, M. (2017). Exploring open educational resources for college Algebra. The International Review of Research in Open and Distributed Learning, 18(4), 50-59. https://doi.org/10.19173/irrodl.v18i4.3003

Colvard, N., Watson, C., \& Park, H. (2018). The impact of open educational resources on various student success metrics. International Journal of Teaching and Learning in Higher Education, 30(2), 262-276.

Dutta, I. (2016). Open educational resources (OER): Opportunities and challenges for Indian higher education. Turkish Online Journal of Distance Education, 17(2), 110-121. https://doi.org/10.17718/tojde.34669

Falconer, I., Littlejohn, A., McGill, L., \& Beetham, H. (2016). Motives and tensions in the release of open educational resources: The UKOER Program. Australian Journal of Educational Technology, 32(4), 92-105. https://doi.org/10.14742/ajet.2258

Ganapathi, J. (2018). Open educational resources: Challenges and opportunities in Indian primary education. The International Review of Research in Open and Distributed Learning, 19(3), 114-128. https://doi.org/10.19173/irrodl.v19i3.3662

Joiner, R., Darling, J., Drew, B., \& Huang, Y. (2012). Digital game based learning for supporting engineering learning in 3 different universities. Paper presented at the $1^{\text {st }}$ STEM Annual Conference, Imperial College, UK.

Jones, K. (2018). The impact of Khan Academy on mathematics achievement (MSc thesis, Kalmanovitz School of Education, California).

Kelly, S. (2018). The impact of Khan Academy math remediation on ninth grade student achievement (PhD dissertation, Liberty University, Lynchburg, Virginia).

Kozinska, K., Kursun, E., Wilson, T., McAndrew, P., Scanlon, E., \& Jones, A. (2010). Are open educational resources the future of e-learning? Paper presented at the Third International Future-Learning Conference: Innovations in Learning for the Future, Istanbul, Turkey.

McShane, M. (2017). Open educational resources: Is the federal government overstepping its 
role? Education Next, 17(1), 18-24.

Mursi, W., Kamal, M., Al-husini, N., \& Mohammed, W. (2013). The effectiveness of individual and participatory electronic games based-computer software in addressing the learning difficulties of computer mathematics among the students of educational technology and their attitudes toward it. Educational and Social Studies-Egypt, 19(3), 267-356.

UNESCO. (2004). Global education digest 2004: comparing education statistics across the world. Montréal: UNESCO Institute for Statistics. Retrieved February 10, 2019, from http://www.unesco.org/education/docs/EN_GD2004_v2.pdf

Williams, H. (2010). Benefits and challenges of OER for higher education institutions. Paper presented at the Workshop Discussions at the Open Educational Resources (OER) Workshop for Heads of Commonwealth Universities Centre for Educational Technology, Cape Town, South Africa.

Yang, J., \& Cotera, R. (2011). Conceptual evolution and policy developments in lifelong learning. Germany: UNESCO Institute for Lifelong Learning. Retrieved February 13, 2019, from http://unesdoc.unesco.org/images/0019/001920/192081e.pdf

Yuan, L., MacNeill, S., \& Kraan, W. (2008). Open educational resources-Opportunities and challenges for higher education. UK: Joint Information Systems Committee (JISC) CETIS. Retrieved February 12, 2019, from http://wiki.cetis.ac.uk/images/0/0b/OER_Briefing_ Paper.pdf

\section{Copyright Disclaimer}

Copyright for this article is retained by the author(s), with first publication rights granted to the journal.

This is an open-access article distributed under the terms and conditions of the Creative Commons Attribution license (http://creativecommons.org/licenses/by/3.0/). 